\title{
CORTE Y CASA REAL DURANTE LA REGENCIA DE MARÍA CRISTINA DE BORBÓN (1833-1840): LA FORMACIÓN DEL “CLAN DE TARANCÓN"
}

\author{
Cristina B. Martínez García \\ (Universidad Rey Juan Carlos) \\ cristinab.martinezg@urjc.es
}

\section{RESUMEN}

A pesar de la pérdida de poder económico y político que experimentó la Casa Real en la nueva estructura del Estado Liberal, la figura del rey (como representante de la nación) aún tuvo fuerza e influencia para empujar a determinados grupos sociales en el ascenso económico y político del nuevo Estado como se observa con los miembros del "clan de Tarancón"; pero es más, la propia familia real se insertó en esta nueva estructura participando en los negocios generados por la nación.

PALABRAS CLAVE: Regencia de María Cristina de Borbón; Casa Real; Fernando Muñoz; Clan de Tarancón; Marcos Aniano.

\section{COURT AND ROYAL HOUSE DURING THE REGENCY OF MARÍA CRISTINA DE BORBÓN (1833-1840): FORMATION OF THE “CLAN OF TARANCÓN"}

\begin{abstract}
Despite the loss of economic and political power experienced by the Royal House in the new structure of the Liberal State, the figure of the king (as representative of the nation) still had strength and influences to push certain social groups in the economic and economic rise. Politician of the new State as observed with the members of the "clan of Tarancón"; but it is more, the own real family was inserted in this new structure participating in the businesses generated by the nation.
\end{abstract}

KEY WORDS: Regency of María Cristina de Borbón; Royal House; Fernando Muñoz; Clan of Tarancón; Marcos Aniano. 
La muerte de Fernando VII supuso un momento crítico para España. Por una parte, los ministros del fallecido monarca estaban participando en la formación de un gobierno que era contrario a los proyectos del rey difunto ${ }^{1}$. Por otra, era por todo el mundo conocido la dramática situación económica en que se encontraba el Patrimonio y la Casa Real, como señalaban las cuentas del nuevo intendente de palacio, Martín de los Heros ${ }^{2}$. A estos problemas había que añadir el deseo de los partidarios de don Carlos, hermano del rey difunto, que lo consideraban como el rey legítimo que debía ocupar el trono en lugar de Isabel II, hija de Fernando VII. Este grupo no sólo era extenso sino que además estaba armado y desperdigado por toda España, por lo que, a pesar de la purga que hubo en el ejército, los partidarios de don Carlos tuvieron fuerza para provocar un enfrentamiento armado, conocido como las Guerras Carlistas, que duró varios años. Paralelamente se organizaban las instituciones políticas del nuevo Estado liberal, bajo la influencia de los dos partidos en los que se habían canalizado las fuerzas sociales (moderados y progresistas), que luchaban entre ellos para conseguir gobernar y de esta manera imponer sus ideales ${ }^{3}$.

En tan complicado panorama político, la actuación de la reina Regente María Cristina de Borbón (viuda de Fernando VII y regente por ser su hija menor de edad), no ayudó a resolver tan problemática situación ${ }^{4}$. A los tres meses de quedarse viuda, María Cristina se casó precipitadamente con un simple guardia de corps, Fernando Muñoz, y aunque intentó mantener su boda en secreto, los embarazos que tuvo al poco tiempo, descubrieron su enlace matrimonial. Así lo manifestó el Eco del Comercio, periódico de ideología progresista, que tomaba como propias las palabras del diputado Pascual pronunciadas cuando se estaba debatiendo en las Cortes un tema tan importante como la tutela de la Reina y su hermana: «no puedo menos de manifestar

\footnotetext{
${ }^{1}$ Antonio Alcalá Galiano, Historias de las Regencias (1833-1843) (Pamplona: Urgoiti Editores, 2012), 3. Ildefonso Bermejo: La Estafeta de Palacio (Historia del reinado de Isabel II). Cartas trascendentales I (Madrid: Imprenta de R. Labajos, 1871-1872), 575-585. Antonio Guzmán de León, El último Borbón. Historia dramática de Isabel II, desde sus primeros años hasta su caída del trono (Barcelona: José Zamora, editor, 1868), 13-20. Manuel Marliani, La Regencia de D. Baldomero Espartero, conde de Luchana, duque de la Victoria y de Morella, y sucesos que la prepararon (Madrid: Imprenta de Manuel Galiano, 1870), 57-80. Luis Garrido Muro, Guerra y Paz. Espartero durante la Regencia de María Cristina de Borbón (Madrid: Centro de Estudios Políticos y Constitucionales, 2016), 25-47.

2 AGP, Administración General, leg. 865. Martín de los Heros de las Bárcenas, Memoria que acerca del Estado de la Real Casa y Patrimonio, y su administración en los últimos cinco meses de 1841, presenta al Excmo. Señor Tutor de S.M. D. Agustín Argüelles, el intendente general en comisión de la misma (Madrid: Aguado, impresor de Cámara de S.M., 1842), 21-23.

3 Antonio Jiménez Landi, Esos días (Madrid: Aguilar, 1965), 78-87. Emilio Laparra López, Fernando VII: un rey deseado y detestado (Barcelona: Tusquets editores, 2018), cap. 8'. Miguel Artola, Partidos y programas políticos, 1808-1836 (Madrid: Aguilar, 1977), I, 204 y ss. Pedro Carlos González Cuevas: Historia de las derechas españolas. (Madrid: Tecnos, 2000), 119-128.

${ }^{4}$ M. A. Casado Sánchez, "María Cristina de Borbón. Una regente cuestionada", en La imagen delpoder. Reyes y Regentes en la España del siglo XIX, Emilio Laparra López (Coord.) (Madrid: Síntesis, 2011), 148156. Isabel Burdiel, Isabel II (Madrid: Taurus, 2011), 177-178.
} 
que tengo convicción de que S. M. se encuentra casada; y estándolo, claro es que ha caducado su Tutela según la letra de la Constitución que nos rige» ${ }^{5}$.

En conclusión, la Regencia de María Cristina (1833-1840) no estuvo exenta de dificultades ni graves acontecimientos y sublevaciones (prueba de ello fueron los sucesos de la Granja de 1836), propiciados, en buena parte, por las torpes decisiones políticas que fue tomando la Regente hasta el punto de que tuvo que abandonar España ${ }^{6}$, siendo sustituida por Baldomero Espartero (1841-1843). Con todo, la regencia del General tampoco se salvó de los problemas, pues además de los que había heredado, también tuvo que lidiar con las conspiraciones orquestadas por la propia María Cristina y su camarilla desde el extranjero?.

\section{ENTRADA DE FERNANDO MUÑOZ EN LA CORTE}

El 28 de diciembre de 1833, sólo tres meses después de la muerte del Rey Fernando VII, la reina viuda María Cristina de Borbón contraía matrimonio con un desconocido guardia de Corps, Fernando Muñoz. Fernando Agustín Muñoz Sánchez (4 de abril 1808-13 septiembre 1873) fue hijo de don Juan Antonio Muñoz Funes y de doña Eusebia Sánchez Ortega, que regentaban un estanco en la villa de Tarancón (Cuenca). La abuela de Fernando, Eugenia Funes, había sido nodriza de la infanta Carlota Joaquina, hija mayor de Carlos IV y María Luisa de Parma. Aprovechando una norma promulgada por el rey Carlos III, que establecía que a las nodrizas de los infantes, así como a sus esposos e hijos, se les premiase con el privilegio de hidalguía, el 30 mayo de 1780, Eugenia Funes obtuvo dicho privilegio ${ }^{8}$. Sin duda, semejante reconocimiento social indujo a que los padres de Fernando Muñoz lo enviaran a la corte en busca de oficio, lo que se tradujo en el ingreso en la compañía de Guardias de Corps.

Según escribió Fermín Caballero9, la Reina Regente conoció a Fernando Muñoz a través de su modista Teresa Valcárcel ${ }^{10}$, quien mantenía unas relaciones amorosas con el guardia de Corps Nicolás Franco, amigo de Muñoz. Éste acompañaba frecuentemente a su amigo a palacio cuando iba a visitar a la modista, circunstancia

\footnotetext{
${ }^{5}$ Discusión de las Cortes sobre la tutela de S. M. la Reina Doña Isabel II y su Augusta hermana, con otros discursos y documentos que la esclarecen, p. 69. Juan Donoso Cortés, Historia de la Regencia de la reina doña María Cristina de Borbón, edición de M. R. Seguí Terol (Madrid: Centro de Estudios Políticos y Constitucionales, 2016), 38-64.

${ }^{6}$ María Ángeles Casado Sánchez, "María Cristina de Borbón. Una regente cuestionada", pp. 148156. Isabel Burdiel, Isabel II, pp. 177-178

${ }^{7}$ Manuel de Marliani, La Regencia de D. Baldomero Espartero. (Madrid: Imprenta de Manuel Galiano 1870), passim.

${ }^{8}$ Trinidad Ortúzar Castañer, Fernando Agustín Muñoz Sánchez, Diccionario Bibliográfico Español.

${ }^{9}$ Fermín Caballero, La cuestión de la Regencia y el Casamiento de María Cristina de Borbón (Madrid: Imprenta del Nuevo Rezado, 1840), 15.

10 Antonio Jiménez Landi, Esos días, p. 125.
} 
que casualmente propició el encuentro informal con la Reina ${ }^{11}$, que se hizo asiduo, prácticamente, desde que se conocieron. Resulta sorprendente que Fernando Muñoz iniciara esta relación cuando era sospechoso de carlista según «el expurgo de $1832 »^{12}$, hasta el punto de que se libró de ser expulsado de la corte por hallarse ausente de ella, aprovechando un permiso concedido para ir a su pueblo, cuando se realizó dicho expurgo.

La atracción de María Cristina hacia Fernando Muñoz trascendió a la sociedad rápidamente: en la semana del 17 de diciembre de 1833 aprovechando que éste ejercía de garzón de palacio, la reina orquestó un viaje a la finca de Quitapesares, cerca de San Idelfonso, a pesar de las inclemencias del tiempo y de los consejos contrarios al viaje que le daban los cortesanos ${ }^{13}$. En esta excursión no acompañó a la reina ninguna mujer, sino que las personas que viajaron en el coche fueron, Francisco Arteaga y Palafox (ayudante general de guardias de Corps), Diego Carbonell ${ }^{14}$ (gentil-hombre) y Fernando Muñoz, que ocupó el asiento delantero junto a María Cristina ${ }^{15}$. A partir de entonces, la carrera social y administrativa de Fernando Muñoz en la casa real fue rápida: a la vuelta del viaje, el 22 de diciembre, fue nombrado gentilhombre con entrada de su Real servicio (cargo creado por Fernando VII), con un sueldo de 30.000 reales anuales; se le otorgó cuarto en palacio, al mismo tiempo que empezó a lucir sobre las solapas de su chaqueta los alfileres y joyas de Fernando VII. En junio de 1844 fue nombrado Grande de España, al mismo tiempo que se le formó el ducado de Riánsares para poder otorgarle tan alto título ${ }^{16}$. Años después, la reina Isabel II lo incluyó en la prestigiosa Orden del Toisón de oro.

Conocida en toda la corte la relación de Muñoz con la Regente, no tardó la prensa de la época en recogerlo en sus páginas. Ejemplo de ello fue la publicación del periódico El Correo del 4 de febrero de 1834 donde se informaba: «Ayer se presentó S. M. la reina gobernadora en char-avant, carruaje abierto, cuyos caballos, dirigía uno de sus criados, y en el asiento del respaldo iba el capitán de guardias, duque de Alagón». Evidentemente, «uno de sus criados» hacía referencia a Muñoz; esta humillación causó gran disgusto tanto a él como a la Regente, por lo que María Cristina, a través del ministro Martínez de la Rosa y del jefe de Policía Latre, ordenó cerrar el diario y desterrar a su editor (Pedro Jiménez de Haro) y a su redactor (Ángel Iznardi) ${ }^{17}$.

${ }^{11}$ Hay otra versión que queda recogida en el libro de Antonio Jiménez Landi siguiendo los escritos de Ángel Fernández de los Ríos donde Teresa estaba casada con un francés de Bayona, pero mantenía relaciones extra matrimoniales con Nicolás Franco, afín a la milicia nacional y guardia de corps.

${ }^{12}$ Fermín Caballero, La cuestión de la Regencia y el Casamiento de María Cristina de Borbón, p. 22.

${ }^{13}$ Ildefonso Bermejo, La Estafeta de Palacio (Historia del reinado de Isabel II), (Madrid: Imprenta de R. Labajos, 1871-1872), I, 592.

14 Diego Carbonell fue gentilhombre de Cámara con ejercicio (AGP, Personal, caja 16752, expediente 25)

${ }^{15}$ Jiménez Landi, Esos días, $p .122$.

16 Augusto de Burgos, Blasón de España, libro de oro de su nobleza: reseña genealógica y descriptiva de la Casa Realy Grandeza de España y los títulos de Castilla. Parte primera: casa real y grandeza de España (Madrid: imprenta de don Pedro Monter, 1859), V, 182-189.

${ }^{17}$ El labriego, sábado 10 octubre 1840, nº 53. 
Como resulta fácil de deducir, Fernando Muñoz tenía muy pocas amistades en la corte y éstas se reducían «al Marqués de Herrera, al escribiente del consulado D. Miguel López Acevedo y al clérigo D. Marcos Aniano González, su paisano, que estaba accidentalmente en Madrid, recién ordenado sacerdote y postrado en cama en la callejuela de Ita" ${ }^{\text {"18. }}$. Precisamente, Muñoz se había dirigido a éste para celebrar su matrimonio, que debía mantenerse en secreto ya que (de ser público) debía pedir permiso a las Cortes que, previsiblemente, no aceptarían dada la procedencia social y la categoría administrativa de Fernando Muñoz $;{ }^{19}$ a cambio, Aniano sería nombrado capellán de honor de la casa real.

No le resultó fácil al joven sacerdote cumplir las ambiciones de su paisano y pariente, porque los deseos personales se contradecían con la reglamentación que existía con el tratamiento que se debía dar a los miembros de la familia real. Según Fermín Caballero, Aniano pidió licencia para realizar el casamiento primero al Patriarca de Indias (capellán mayor de la casa real), quien se la negó debido a la categoría de las personas que contraían matrimonio y la falta de relevancia eclesiástica del sacerdote. Ante este contratiempo, el joven sacerdote pensó que lo más conveniente era acudir a su superior eclesiástico, el obispo de Cuenca, de quien obtuvo la misma respuesta negativa. Finalmente, la consiguió gracias al nuncio de su Santidad, el Cardenal de Tiberi, no sin tener que utilizar la mediación de la reina regente, pues, el nuncio tampoco consideraba a Aniano digno de presidir tan gran evento. Años más tarde, María Cristina se enteró de que este matrimonio careció de legitimidad ya que Aniano no reunía las debidas licencias para administrarlo y, además, no se cumplían los preceptos de las leyes civiles vigentes ${ }^{20}$. Con todo, el 28 de diciembre de 1833, a las siete de la mañana, se llevó a cabo el matrimonio morganático, siendo ministro del sacramento don Marcos Aniano «y testigos el marqués de Herrera y don Miguel López de Acebedo; y haciendo de asistente el presbítero don Acisclo Ballesteros». ${ }^{21}$

Una vez celebrada la ceremonia, las intenciones de ambos cónyuges se mostraron diversas: a Fernando Muñoz le preocupaba la situación indefensa y sin partidarios que tenía en la corte, propia de un «hombre nuevo», sin cargo relevante en la administración; a María Cristina le obsesionaba estar a solas con su flamante esposo (a quien irónicamente, en ciertos círculos políticos, comenzaron a llamarle «Fernando VII») para lo que la corte ni la casa real era el mejor lugar, por lo que proyectó visitar los sitios reales, concretamente se marcharon a Aranjuez y después a San Ildefonso. Con el fin de evitar murmullos y habladurías cortesanas, Fernando Muñoz y su esposa no tardaron también en alejar de Madrid a los testigos de su enlace: a Teresa Valcárcel

\footnotetext{
${ }^{18}$ Fermín Caballero, La cuestión de la Regencia y el Casamiento de María Cristina de Borbón (Madrid: Imprenta del Nuevo Rezado, 1840), 15.

${ }^{19}$ Ildefonso Bermejo, La Estafeta de Palacio (Historia del reinado de Isabel II), I, 593-596.

${ }^{20}$ Antonio Jiménez Landi, Esos días, 128.

${ }^{21}$ Fermín Caballero, La cuestión de la Regencia y el Casamiento de María Cristina de Borbón, 16. Fermín Caballero añade que «tuvieron conocimiento de este enlace la Teresita Valcárcel y la moza de retrete llamada Antonia [Robledo]», que asistieron por parte de la novia. Carbonell, aunque no estuviera presente también estaba enterado del suceso. El expediente de Antonia Robledo en AGP, Personal, caja 888, expediente 5 .
} 
se la destinó a Bayona con un escribano que diera fe de ello, Nicolás Franco fue elevado a Coronel destinado a Jaca, mientras a Carbonell, gentilhombre de cámara, se le obligó a residir en Andalucía. Paralelamente, y con el mismo esfuerzo, se dispuso a forjar un grupo de seguidores de plena confianza que controlasen la casa real y se informasen de las habladurías y críticas que en los sectores cortesanos se hacían al flamante matrimonio.

Evidentemente, los personajes que Fernando Muñoz era capaz de apadrinar (dado que no era un gran patrón cortesano) no podían tener rancia genealogía ni ser políticos de reconocido prestigio; es decir, no podían ser miembros destacados del partido moderado (ni tampoco carlista, que pretendían instaurar en el trono a don Carlos) por lo que recurrió a parientes y paisanos suyos (de origen rural, con baja cultura, pero fieles a su persona) a los que les concedía un oficio en palacio. De esta manera, servir la casa real se confundió con el trabajo mecánico doméstico ya que desconocían los reglamentos y etiquetas del servicio. El resultado fue, como sentencia Fermín Caballero:

Una sensualidad estragada y de baja ralea ha infeccionado los salones de palacio; una familia sin educación ni saber se ha apoderado de la voluntad de la reina, y la camarilla ha degenerado hasta lo más vil y estúpido de la sociedad. La inocente Isabel no sabe ni tiene más maestros a la edad de diez años que de leer y escribir y con el trato y el aprendizaje de los Muñozes habrá de casarse de aquí a dos años ${ }^{22}$.

\section{EL «CLAN DE TARANCÓN»COMO FACCIÓN CORTESANA}

Así pues, Fernando Muñoz recurrió a sus familiares y amigos de Tarancón, personas ajenas a todo comportamiento cortesano, ${ }^{23}$ pero que le ofrecían una inquebrantable obediencia. A partir de este grupo, Fernando Muñoz se esforzó por articular una facción (creo que se puede denominar con toda legitimidad el «clan de Tarancón»), que controlase la casa real; una red de servidores y espías, que le tuvieran informado de las habladurías y sucesos de la corte. Este grupo aumentó paulatinamente durante la regencia (sobre todo a partir de 1843) añadiéndose no solo nuevos familiares y amigos, sino también conocidos o clientes originarios de pueblos manchegos en torno a Tarancón. Muñoz era consciente de las limitaciones de su clientela por lo que proyectó un plan para que su grupo pudiera codearse con las facciones cortesanas tradicionales y de esta manera tuviera efectividad política. Para lograrlo, en primer lugar, introdujo a sus clientes en los cargos de administración de la casa y en los sitios reales, de manera que, además de controlar la hacienda real, se enriquecían con los salarios que se les pagaba y con los negocios (y favores) que hacían, derivados de su actuación administrativa. Para estos cargos no se necesitaba tener grandes títulos ni rancia genealogía como exigían los moderados, sino osadía y ambición de riqueza. En segundo lugar, con el paso del tiempo, estos mismos clientes fueron ascendidos a

\footnotetext{
${ }^{22}$ Fermín Caballero, La cuestión de la Regencia y el Casamiento de Maria Cristina de Borbón, 22.

23 Antonio Jiménez Landi, Esos días, 127.
} 
oficios palatinos (que venían siendo ocupados por títulos nobiliarios o por personajes con tradición en el servicio real) bien a través de la vía matrimonial (enlaces con hijos e hijas de oficios) o bien por nombramientos otorgados por la Reina Regente, evidentemente, con el concurso y mediación de Fernando Muñoz ${ }^{24}$. Como estoy estudiando ahora, el grupo se fue diversificando y entró en conexión con financieros que hacían sus negocios en las grandes obras del Estado (ferrocarriles, comercio en La Habana, en Londres, etc. ${ }^{25}$ ) al mismo tiempo que se convirtieron en un eje político amplio, que controló las diputaciones provinciales durante las décadas centrales del siglo XIX e hizo notar su inmensa influencia en la evolución política del Estado hasta los tiempos del general Prim.

El núcleo original de este poderoso grupo se formó en los años 1833-34, es decir, al poco de celebrarse el matrimonio, como señalaba con desdén el progresista Fermín Caballero, también casi paisano de Fernando Muñoz ${ }^{26}$, por: «La camarilla interior de Cristina la componen estos elementos: los padres de [Fernando] Muñoz; su hija Alejandra, camarista; D. José Muñoz, contador del patrimonio; D. Marcos Antonio González, confesor de S. M., capellán de honor, administrador del Buen Suceso, prebendado de Lérida y deán de La Habana; D. Juan González Cabo-Reluz, afrancesado, ayo de la reina Isabel ${ }^{27}$; D. Serafín Valero, hijo del dómine de Tarancón, administrador de Vista-alegre; D. Miguel López Acebedo, director de la Casa de la Moneda; D. Antonio García del Castillo, afrancesado, administrador que ha sido de la Casa de Campo, del alcázar de Sevilla, etc.; el exjesuita Muñoz, y otros de esta jaez»» ${ }^{28}$.

Con todo, el grupo de Fernando Muñoz no resultaba tan exiguo ni sus componentes eran tan incompetentes como quiere dar a entender Fermín Caballero. Aunque un análisis más amplio constituye el objetivo de otros trabajos que estoy realizando, ahora me propongo dar a conocer (aunque sea brevemente) los componentes del grupo y el lugar que ocuparon en la Casa Real hasta convertirse en una facción de la política española del siglo XIX.

\footnotetext{
${ }^{24}$ Sobre el tema de los grupos de poder, me remito a Pilar Toboso Sánchez, "Las redes de poder en el mundo contemporáneo" Ayer 105 (2017): 13-22.

25 Ángel Bahamonde Magro y José Cayuela Fernández, “Traficantes, armadores y hacendados: elite colonial hispano-cubana y trasvase de capitales en el siglo XIX” Studia Historica: Edad Contemporánea 15 (1997): 9-20

${ }^{26}$ Fermín Caballero había nacido en Barajas de Melo (Cuenca) el 1800, hijo de labradores con numerosas propiedades agrícolas. Estudió en el seminario de san Julián de Cuenca y después en Zaragoza y en la universidad de Alcalá. Emigró tras 1823 por declararse progresista y regresó a España tras la muerte de Fernando VII. Fundó el periódico el Eco del Comercio, del que fue su director y ocupó diversos cargos en la administración del Estado. Casó con Paula Heredero, no tuvieron hijos. Fue diputado en las Cortes del Estatuto de 1834; además permaneció diputado y senador entre 1834 y 1842. Murió en 1876.

27 Pariente de Marcos Aniano González.

${ }^{28}$ Ibid, 22-23. Por cierto, el exjesuita Muñoz, al que despectivamente se refiere Fermín Caballero, se llamaba Gregorio Muñoz (1813-1851), natural de Tarancón y hermano de Fernando Muñoz, Catálogo de Jesuitas de la Provincia de España (Archivo de la Compañía de Jesús de Alcalá de Henares). No aparece clara la evolución personal de este jesuita, que fue enviado a La Habana y expulsado de la corte, lo que lleva a Fermín Caballero a mencionarlo con menosprecio.
} 


\section{1. Los patronos del «clan de Tarancón»}

Entre los personajes más representativos del "clan de Tarancón" se encontraban, en primer lugar, los padres de Fernando Muñoz: don Juan Antonio Muñoz Funes Carrillo y doña Eusebia Sánchez Ortega. Este matrimonio tuvo siete hijos, por este orden: José Antonio Muñoz Sánchez, Agustín Fernando Muñoz Sánchez, Juan Gregorio Muñoz, Jesús Muñoz, Anastasia y Juliana (que murieron jóvenes) y Alejandra Muñoz ${ }^{29}$. Muy pronto escalaron relevantes puestos en la sociedad; ahora bien, más que como grandes patronos, parece que le otorgaron numerosos títulos de acuerdo al respeto que debían tener por ser los padres de Fernando Muñoz: el 12 de diciembre 1846 la reina Isabel II les extendían el título de conde de Retamoso, previamente le había otorgado el título de Vizconde de Sabiñán, para entonces, ya tenía título de caballero de la Orden de Santiago y administrador del Real Cortijo de San Isidro de Aranjuez.

No obstante, los tres grandes patronos del "clan de Tarancón" fueron: José Antonio Muñor, hermano de Fernando; Marcos Aniano, paisano y pariente de los Muñoz y, por el lado femenino, Alejandra Muñoz, hermana de Fernando y José Antonio.

- La actividad de José Antonio Muñoz

Sin duda ninguna, el gran patrón y baluarte de la familia Muñoz en la corte fue José Antonio Muñoz, nombrado (por mediación de su hermano) contador del Patrimonio de la Real Casa. José Antonio Muñoz constituyó el eje y punto de referencia de todos los miembros de su familia y amigos; él era quien distribuía y señalaba los cargos adecuados para cada uno de los familiares que desde el pueblo se acercaban a la corte en busca de oficio (esto es, de situar a los miembros del "Clan"); en sus cartas se observa la preocupación y atención (propias de un patrón) por la situación o problemas (por lo general, económicos) que podían tener sus numerosos parientes, lo que incluía también la defensa y exculpaciones que hacía de Fernando Muñoz cuando algún familiar se quejaba de que éste no le correspondía a sus peticiones ni contestaba a sus cartas. A lo largo de la correspondencia que mantuvieron ambos hermanos durante su vida, se constata que José Antonio era considerado la columna vertebral del "clan de Tarancón" y que Fernando mantuvo en su hermano una confianza inquebrantable, no solo por su fidelidad, sino también por su inteligencia y capacidad en los asuntos económicos y administrativos, consultándole siempre las decisiones más importantes. Ambos hermanos (Fernando y José Antonio) tuvieron muy claro la importancia que tenía la casa real (su pertenencia a ella) para conseguir los objetivos que se propusieron.

Precisamente, la personalidad de José Antonio Muñoz y su capacidad para desempeñar oficios en la administración y de gestión se manifestó ante todo en la

29 Augusto de Burgos, Blasón de España. Libro de Oro de su nobleza: V, 187-189. 
indiscutible actividad que ejerció en el proceso de cambio de las estructuras de la casa real de la Monarquía absoluta hasta adaptarla a la casa real del Estado liberal ${ }^{30}$.

La Constitución de 1812 situaba a la casa real como un organismo del nuevo Estado liberal ${ }^{31}$, que era una función muy distinta a la que había venido desempeñando en la Monarquía desde la Baja Edad Media hasta el siglo XIX (cuando el rey era el dueño de la Monarquía), por lo que era forzoso la readaptación o supresión de los departamentos que componían la tradicional casa, así como la separación de los bienes de la nación del patrimonio real (propiedades y sitios reales) ${ }^{32}$, formando, a partir de entonces, el organismo denominado «Real Casa y Patrimonio» dentro del Estado ${ }^{33}$. La ruptura que se había producido entre la economía de la Real Casa y de la hacienda de la Monarquía hizo imposible restaurar la organización de la Casa tradicional cuando Fernando impuso el absolutismo en 1814, por lo que tuvo que adaptarse a las nuevas circunstancias y crear organismos (por lo general unipersonales) de acuerdo a las nuevas funciones que la Casa debía cumplir ${ }^{34}$.

La transformación institucional que realizó Fernando VII en la nueva Real Casa durante sus primeros años de su reinado consistió en fijar como los cargos más importantes al Mayordomo mayor y al Veedor. En decreto de 22 de mayo, Fernando VII dispuso que el Mayordomo Mayor ejerciese las funciones gubernativas, tanto relativas a la Real Casa como al Real Patrimonio «separando enteramente el gobierno e interés de mi Real Casa de los demás del Estado» ${ }^{35}$. Junto al Mayordomo mayor se creó la Secretaría de la mayordomía. Por otro Decreto de 9 de agosto de 1815 se implantó también

\footnotetext{
30 AGP, Administración General, leg. 865, Martín de los Heros de las Bárcenas, Memoria que acerca del Estado de la Real Casa y Patrimonio, y su administración en los últimos cinco meses de 1841, 21-23.

${ }^{31}$ Francisco Sainz de Varanda, Colección de leyes fundamentales, 47. Un análisis de este Discurso, Fernández García, La Constitución de Cádiz. (1812) y Discurso preliminar a la Constitución. Miguel Artola y Rafael Flaquer Montequi, La Constitución de 1812 (Madrid: Iustel, 2008), 107. J. Varela Suances-Carpegna, La Monarquía doceañista (1810-1837). (Madrid: Marcial Pons, 2013), 196-197.

32 Sainz de Varanda, Colección de leyes fundamentales, 47. Un análisis de este Discurso, Antonio Fernández García, La Constitución de Cádiz. (1812) y Discurso preliminar a la Constitución. Ramos Santana, Constitución política de la Monarquía española, promulgada en Cádiz el 19 de marzo 1812. Carmen y Encarna García Monerris, «La nación y su dominio: el lugar de la Corona». Historia Constitucional (Revista electrónica), no 5 (2004), pp. 160-191. Idem, "Monarquía y patrimonio en tiempos de Revolución en España". Diacronie. Studi di Storia Contemporanea 16 (2013): 2. ID., Las cosas del rey, (Madrid: Akal,2015).

33 Francisco Cos Gayón, Historia jurídica del Patrimonio Real (Madrid: Imprenta de Enrique de la Riva, 1881), 150-151.

${ }^{34}$ Benito Ortega, Garzón Guzmán, González Pañero, y Mairal Domínguez, "La Jefatura de Oficios y Aposentamiento de la Real Casa y Patrimonio (1814-1931)" Reales Sitios, 174 (2007): 48-50. AGP, Reinados Isabel II, caja 345, exp. 4. Ángel Menéndez Rexach, "La separación entre la casa del rey y la administración del Estado (1814-1820)".

35 Reglamento de la real casa. (Madrid. Imprenta real, 1829). Reglamento que para el régimen y gobierno de la Real Casa mandó el Rey Ntro Señor que se observase por su Real Decreto de 16 de noviembre de 1822. AGP, Administración, leg. 942. Véase también, Dolores del Mar Sánchez González, "El tránsito de la Casa de Fernando VII a la de Isabel II: la Junta de Gobierno de la Casa Real y Patrimonio (1815-1840)", en los apéndices presenta los curricula de todos los Mayordomos mayores de la casa real de Fernando VII. Dolores del Mar Sánchez González, "La nueva planta para la Casa Real de Fernando VII: El Desconocido Reglamento de 17 de noviembre de 1815", Cuadernos de Historia Moderna 2003, Anejo II, 311-343.
} 
una Junta Gubernativa compuesta por el mayordomo como presidente, del secretario, contador, tesorero, asesor y fiscal, para todos los asuntos de la Real Casa y Patrimonio ${ }^{36}$, al mismo tiempo que elegía a los personajes que iban a ocupar dichos cargos ${ }^{37}$.

La veeduría general de la Real Casa, Capilla y Cámara se creó el 2 de junio 1814. Bajo el mando directo del veedor actuaban todos los jefes de los oficios que componía la servidumbre regia, por lo que este importante oficio se erigía en puente imprescindible entre estos y el Mayordomo Mayor. La veeduría general se mantuvo durante el reinado de Fernando VII; pero el 3 de septiembre 1834 se promulgaba un decreto en el que se suprimía dicho cargo; en el decreto se alegaban razones de incompatibilidad con el nuevo orden administrativo que la Reina Gobernadora pretendía implantar ${ }^{38}$. A partir de entonces cada uno de los oficios de la casa quedaba bajo la supervisión de su respectivo jefe en lo relativo al gobierno del mismo, mientras que en lo económico todos los negocios pasaron a Contaduría ${ }^{39}$.

Dos meses después, María Cristina decretaba la creación de la Alcaldia $^{40}$. Con ello pretendía controlar el palacio tras la muerte de Fernando VII. Esto hizo que el Alcaide se convirtiera en una de las principales figuras de la corte durante la regencia. Durante la existencia de la Alcaldía (1834-1852), la Real Casa y Patrimonio experimentaron numerosos cambios: Entre 1834-1838: la Mayordomía mayor se ocupó del gobierno-etiqueta y de la economía. Pero 1838 se dividieron sus funciones: el Mayordomo mayor se ocupó de la etiqueta-gobierno, mientras se creaba el intendente general de la real casa y patrimonio (que se ocupaba de los asuntos económicos) ${ }^{41}$. Esta organización era realmente una novedad, porque rompía formalmente la tradicional primacía del Mayordomo mayor, relegándole a un puesto puramente protocolario y limitado. Pero además, obligó a trazar terminantemente la línea de separación que debe existir entre las funciones de etiqueta y ceremonia de palacio y las económicoadministrativas de la real casa y patrimonio. Ello supuso una auténtica «revolución palaciega», que no sería pacíficamente aceptada. La etiqueta quedó en manos de los «políticos», los tradicionales personajes nobles, que buscaban el medro a través de la relación con el monarca, mientras que el patrimonio (asignación anual de las Cortes y

${ }^{36} \mathrm{Ha}$ sido estudiada por Ángel Menéndez Rexach, La jefatura del Estado en el Derecho público español, (Madrid, Universidad Autónoma de Madrid, 1978. Tesis doctoral) I, 465 ss. y por Sánchez González, "El tránsito de la casa de Fernando VII a la de Isabel II: la Junta de Gobierno de la Casa Real y Patrimonio (1815-1840)", en Corte y Monarquía en España, Sánchez González, Dolores del Mar (Coord.): (Madrid, 2003), 29-66.

37 AGP, Registro 5710, fols. 10r-12r.

${ }^{38}$ En realidad se había implantado para controlar la ideología y afecto de los servidores de la casa al monarca, Pere Molas Ribalta, Del absolutismo a la constitución. La adaptación de la clase política española al cambio de régimen (Madrid: Silex, 2008), cap. 205 ss. Antonio Manuel Roncal, ¡El enemigo en palacio! (Madrid: Publicaciones Universidad de Alcalá, 2015)

${ }^{39}$ Benito Ortega, Garzón Guzmán, González Pañero, y Mairal Domínguez, "La Jefatura de Oficios y Aposentamiento de la Real Casa y Patrimonio (1814-1931)”, 50. AGP, Reinados Isabel II, caja 345, exp. 4.

40 AGP, Administración General, leg. 408.

${ }^{41}$ El 30 de septiembre 1838, desde la Intendencia General se distribuyó el reciente (aprobado en ese mismo día) reglamento para «el régimen y gobierno de la Real Cocina y Ramillete» (AGP,Isabel II, caja 342 y AGP, Administración General, leg. 942) 
administración de los bienes y sitios reales) quedó en manos de los administradores (intendente).

Fernando Muñoz comprendió con exactitud la trascendencia de este cambio y tuvo muy claro que la riqueza que aún tenía la casa real, no residía en la casa real en cuanto organismo del Estado liberal, sino en el patrimonio de la reina, por lo que colocó a su hermano José Antonio en un cargo importante que dirigiera la transformación institucional; por decreto autógrafo de su Majestad, el 18 de diciembre de 1837 se nombraba a José Antonio Muñoz, «administrador que fue de Aranjuez, para la plaza de Contador general de la Real Casas ${ }^{42}$; desde este puesto, no solo colaboró en las reformas estructurales que se llevaron a cabo, sino que también lo aprovechó para vigilar los nombramientos que se hacían en los nuevos cargos, introduciendo a su clientela en los oficios subalternos y como administradores de los Sitios Reales ${ }^{43}$. Para sellar y dejar asentadas dichas reformas, se publicaron nuevas Ordenanzas de la casa. El 26 diciembre de 1837, José Antonio Muñoz mandaba una orden desde la Contaduría de la casa real y patrimonio de $S$. $M$. a todos los jefes de oficios en la que se solicitaba ${ }^{44}$.

José Antonio Muñoz, no solo fue Contador General de la Real Casa, sino que poco después, Isabel II le nombraba también gentilhombre de Cámara y Apoderado general de la Infanta $D^{a}$. Ma Luisa Fernanda. Ciertamente, la responsabilidad y celo con que desempeñó sus oficios están fuera de duda; no solo denunciaba la corrupción que existía en determinados departamentos, sino que hasta realizó una reducción de salarios en su departamento para ahorrar gastos dada la caótica situación económica de la casa real. La cantidad de reales de vellón que se ahorraron por esta reducción ascendió a 184.800 anuales

Con todo, la actividad e influencia de José Antonio Muñoz no se ciñó solamente al campo económico; como resulta fácil de deducir, también aconsejó y propuso a la Regente y a su esposo las personas que debían ser depuradas de palacio, por no ser partidarias de la Regente (la red clientelar que tenía, le permitía estar informado de lo que pensaban los ministros y oficiales palaciegos), al mismo tiempo que presentaba una larga lista de personas para ocupar todos los cargos de la economía, que estaban bajo su control.

- La actividad de Marcos Aniano González Muñoz

El otro gran patrón del "clan de Tarancón” fue don Marcos Aniano González Muñoz nacido en Tarancón, el 25 de abril de 1809, en el seno de una familia rural acomodada. Sin duda ninguna, representó la sección culta del grupo de Tarancón. Su padre, Gabriel José González Cabo-Reluz, era hijo del abogado de los Reales Consejos, Agustín González Sánchez, y nieto, por parte materna, del notario José Cabo-Reluz y Pastrana, natural de Ocaña. De su madre, María Josefa Muñoz y Baracaldo, existen

\footnotetext{
${ }^{42}$ AGP, Personal, caja 731. Exp. 1.

43 AGP, Administración general, leg. 409.

${ }^{44}$ AGP, Administración General, leg. 942.
} 
menos datos. Parece ser que su bisabuelo fue hermano del bisabuelo de Fernando Muñoz. El matrimonio tuvo, además de Marcos, dos hijas más: Gregoria y Tomasa.

Como buena parte de los miembros de su familia, Marcos Aniano realizó sus estudios en la Universidad de Alcalá, donde se licencióen cánones y alcanzó el grado de bachiller en leyes. En una carta del 15 de enero de 1834 figura que pagó 200 reales de vellón en concepto de los derechos por la expedición del título de abogado de los Reales Consejos ${ }^{45}$. A partir del matrimonio secreto celebrado entre Fernando Muñoz y la regente María Cristina su carrera ascendió en la Casa Real, acumulando cargos y numerosas rentas. Ya en los primeros días de 1834, se presentó una petición a la Regente para que le nombrase capellán de honor ${ }^{46}$, siendo nombrado además cura de la parroquia ministerial del Real Palacio el 10 de junio de 1834. Este nombramiento coincidía con la reforma que hacía la Regente de la Real Capilla ${ }^{47}$. Para entender la influencia de Marcos Aniano en la capilla y en los cambios que se estaban produciendo, es preciso conocer la reforma que ordenó la Regente en $1834^{48}$. Parece que la reforma fue demasiado restrictiva en el afán de ahorrar gastos, pues, años más tarde se hacía referencia a ella en ese tono ${ }^{49}$.

En real orden de 24 de abril de 1834 se remitió a la contaduría general una lista de los capellanes de honor que habían asistido a los actos de la real capilla durante el mes de marzo de 1834 en que consta que Aniano había tomado posesión el día 14 de marzo dicho y no había tenido falta hasta el 28 del mismo en que se marchó con licencia tempora ${ }^{50}$. Por Real Orden de 29 de marzo de 1835, se comunica

haberse dignado S. M. resolver por Real Decreto autógrafo de 27 del mismo, que diga en un todo el decreto de la última planta dada a la Real Capilla, igualándose todos los capellanes de honor antiguos, con el sueldo que aquel señalada, puesto que se hallan en el mismo caso que los demás empleados de la Real Casa que percibían sueldos personales o dos, y se les ha quitado.

Por otra orden de 4 de mayo del mismo año, se ordenaba que se abonase a Marcos Aniano, por la Tesorería general de la Real Casa, el mismo sueldo que gozaba antes de publicarse el arreglo definitivo de la Real Capilla de 26 de Junio de $1834^{51}$. Casi un año después de ser nombrado capellán de honor, el 11 de septiembre de 1834, Aniano fue nombrado administrador del Buen Suceso. Para comprender la

45 AGP, Personal, caja 458, exp. 44

46 AGP, Personal, caja 458, exp. 44. Madrid, 2 de enero 1834.

${ }^{47}$ Fechado el 8 de julio de 1833. AGP, Administración General, leg. 1132.

48 "Lo tendréis así entendido y dispondréis lo conveniente a su cumplimiento. Está rubricado de la Real mano. Carabanchel, 26 de junio 1834. Al marqués de Valverde" (AGP, Administración General, leg. 1132).

${ }^{49}$ Madrid 10 de mayo 1852. AGP. Administración General/ capilla. Caja 6837. A continuación se presentaba "Nueva planta de la capilla real aprobada por S. M. en despachos de 17 de abrily 27 de junio de 1852".

50 AGP, Administración General, leg. 1132.

51 AGP, Personal, caja 458, exp. 44 
importancia y fundamento de este nombramiento, es preciso recordar la importancia de este hospital ${ }^{52}$.

A pesar de acumular numerosos cargos en tan poco tiempo, Aniano era consciente de la débil situación que tenían en la corte tanto él como sus benefactores, María Cristina y Fernando Muñoz, debido a las críticas y empuje del partido progresista, que finalmente les obligaron a que salieran del país ${ }^{53}$; y no tenía muy claro cuál sería su suerte después de la salida del matrimonio regente de la península, por eso, pidió que María Cristina le concediese licencia por un año para que, bien en el Reino o en el país extranjero que más le conviniese, pudiera cuidar del restablecimiento de su salud, "habiendo entre tanto percibido íntegro su sueldo siempre que observe las circunstancias que percibe el artículo 783 de la ordenanza general" y —se añadía como aclaración- "empezó a hacer uso de dicha licencia en 17 al referido mes" ${ }^{\text {". No se }}$ equivocó Aniano en sus cálculos, pues, el 12 de octubre de 1841, por orden de Agustín Argüelles, se le separaba (al igual que a todos sus compañeros de la casa) ${ }^{55}$ de la capellanía de honor y de cualquier otro encargo que tuviera dependiente de la Real Casa, bajo el argumento de que se hallaba ausente en Francia siguiendo a la señora Reina Madre, por lo que no servía dicha capellanía, ni la administración del hospital del buen Suceso, ni la fiscalía de la real capilla que tenía a su cargo, ni mucho menos el deanato de la santa iglesia de La Habana que según, informe del Gobierno, también poseía $^{56}$. La expulsión de Aniano y de todos los servidores de la casa real, en 1841, fue acompañado por una renovación completa del servicio de la casa de Isabel, introduciendo a personas progresistas ${ }^{57}$. La tarea de realizar el relevo fue encomendada a Agustín Argüelles ${ }^{58}$.

Con todo, la regencia del general Espartero no estuvo exenta de problemas, pues, dos años después de asumirla se vio obligada a abandonarla, en $1843^{59}$, volviendo

52 AGP, Personal, caja 458, exp. 44. «Teniente general de Casa del Real Palacio interinamente y por Real Orden de 11 de septiembre siguiente pasó al fiscal de la Real Capilla con el sobresueldo de $20 \mathrm{r}$ anuales el nuevo reglamento; nombrándole S.M. al mismo tiempo Administrador del Buen suceso». AGP, Reinados. Fernando VII, caja 11, exp. 13. «Manual que comprende todas las propiedades que posee en esta Corte S. M. la Reyna $\mathrm{D}^{\mathrm{a}}$ Isabel $2^{\mathrm{a}}$. Contiene, asimismo, varias otras noticias y observaciones de interés para la Real Casa. Dedicado a S. M. la Reyna Gobernadora, por su muy fiel y reconocido criado Salvador Enrique de Calvet. Año 1836».

53 Manuel de Marliani, La Regencia de D. Baldomero Espartero, conde de Luchana, duque de la Victoria y de Morella, y sucesos que la prepararon, 216. El Conde de Romanones, Espartero, el general del pueblo (Madrid: Espasa-Calpe, 1932), 109.

54 AGP, Personal, caja 458, exp. 44. Madrid 15 de abril de 1839.

55 Juan Donoso Cortés, Historia de la Regencia de la reina doña María Cristina de Borbón, edición de María Rafaela Seguí Terol (Madrid: Centro de Estudios Políticos y Constitucionales, 2016), 70-79.

${ }^{56}$ AHN, Diversos Titulos Familias, 3390, leg. 93, exp. 7, doc. 114.

${ }^{57}$ AGP, Administración General, leg. 865, pp. 82-89.

58 AGP, Administración General, leg. 865. Manuel Marliani, La Regencia de D. Baldomero Espartero, conde de Luchana, duque de la Victoria y de Morella, y sucesos que la prepararon, 231. P. Díaz Marín, La monarquía tutelada. El progresismo durante la Regencia de Espartero (1840-1843). (Alicante: Publicacions Universitat d'Alacant, 2015), 108

${ }^{59}$ Manuel de Marliani, La Regencia de D. Baldomero Espartero, conde de Luchana, duque de la Victoria y de Morella, y sucesos que la prepararon, 597-602. El Conde de Romanones, Espartero, el general del pueblo, 130- 
a ocuparla María Cristina de Borbón, al mismo tiempo que restituía en sus cargos a los que habían sido desposeídos: «Por otra orden del Sr. Tutor [duque de Bailén] en noviembre $1^{\circ}$ comunicada a esta contaduría en 19 del mismo mes y año de 1843 , se le repone en la Capellanía de Honor, de fiscalía de la Capilla y Administrador del Real Hospital del Buen Suceso. En 26 de noviembre juró y tomó posesión de sus destinos en que fue repuesto, según oficio de 13 de diciembre», así como la liquidación de haberes que le correspondían en concepto de Capellán de honor y fiscal de la Patriarcal y en el de confesor de la Reina Madre. Para ello, se realizó un informe sobre la conducta que había seguido Aniano desde la salida de María Cristina de la península ${ }^{60}$.

El breve período de tiempo que duró el exilio (1840-1843) sirvió a los grandes patronos del clan de Tarancón -y en especial a Fernando Muñoz-para darse cuenta de la debilidad de su grupo en la corte y de la necesidad de buscar los medios para ampliar su influencia en la casa real y vincularse a otras redes políticas de mayor relevancia social $^{61}$. La correspondencia que Marcos Aniano mantuvo con Fernando Muñoz durante los años de su ausencia (1841-1843) iba en esta dirección, al mismo tiempo que le ponía al día de todos los movimientos y habladurías de las camarillas cortesanas y de la evolución de los negocios que manejaba la familia $\mathrm{Muñoz}^{62}$. La vuelta de la Regente y Fernando a Madrid no resultó agradable como demuestra la meticulosa situación cortesana que Aniano hacía a Fernando en carta de 30 de septiembre de 1843. Pero además, tuvieron que verse con los progresistas que habían ocupado los cargos, lo que no le resultaba agradable ${ }^{63}$.

Los recelos acerca de la fidelidad de los personajes eran grandes y la vuelta tenía que hacerse con garantías de asentarse firmemente en la corte. Aniano pensaba que la reina regente, María Cristina, tenía demasiada autonomía a la hora de hablar con el grupo opositor y no daba cuenta ni consultaba a su esposo, por lo que recomendaba a Fernando Muñoz que controlase a su esposa y que la política cortesana se hiciera de acuerdo a sus intereses. A los personajes había que analizarlos detenidamente para saber sus ideas y grado de fidelidad. Por eso, le pedía a Fernando Muñoz que aplicara

132. Adrián Shubert, Espartero, el pacificador (Barcelona: Galaxia Gutenberg, 2018), 302-304. Javier Pérez Núñez, "Los amigos de Espartero: la construcción de la red de los Ayacuchos" Ayer 105 (2017): 79-102.

${ }^{60}$ Intendencia General de la Real Casa y Patrimonio. Palacio 22 de noviembre de 1841. Sr. Secretario de estado y del Despacho de Gracia y Justicia (Ibid.).

${ }^{61}$ El origen de los partidos políticos: Artola, Partidos y programas políticos, 1808-1836, I, 204-406. González Cuevas, Historia de las derechas españolas, 126-128.

62 AHN, Diversos Titulos Familias, (3390, leg. 93, exp. 7). En este legajo se encuentran 30 misivas de diferente índole, fechadas entre los años 1841 y 1844, época que coincide con la regencia de Espartero. En ellas se puede observar la relación íntima y de confianza que tenían los dos amigos y cómo el presbítero le ponía al día sobre los asuntos que ocurrían en la corte. Además de hablar de los negocios que ambos tenían entre manos. También hay algunas cartas dirigidas a María Cristina, muchas de ellas están fechadas desde el Real sitio de Gózquez, donde — como decía el propio Marcos- se desplazaba con frecuencia a este lugar para cazar perdices.

${ }^{63}$ AHN, Diversos Titulos Familias, 3390, leg. 93, exp. 7, doc. 255, carta de Aniano a Fernando Muñoz, fechada el 3 octubre 1843. 
la prudencia cortesana cotidiana ${ }^{64}$ y fuera ganando la amistad de personajes que ocupaban cargos importantes ${ }^{65}$. El hecho de que Marcos Aniano fuese también confesor de la Reina Regente, le valió para convencerla de las decisiones que debía tomar que, sin duda, estaban de acuerdo con el reforzamiento político del clan en la corte.

- La actividad de Alejandra Muñoz

El tercer elemento fuerte de este clan fue la hermana de Fernando Muñoz, Alejandra Muñoz, a quien muy pronto (4 de junio de 1838) se le introdujo en la casa real como camarista de la de la Infanta Luisa Fernanda. Una lectura atenta de la correspondencia de los diferentes miembros del "clan de Tarancón" demuestra que la importancia social de Alejandra no se debió tanto a su personalidad y dotes políticas cuanto al empeño que todos sus hermanos realizaron para convertirla en el enlace del "clan" con la alta sociedad. Desde el principio, la familia pretendió introducirla en la corte y que alcanzase un matrimonio ventajoso. Proyecto que, a tenor de la misiva que le envió Fernando Muñoz a su hermano Juan Gregorio Muñoz, no lo consiguió ${ }^{66}$.

Es más, la vida de Alejandra en la corte no parece que fuera cómoda; en 1841 fue cesada por Argüelles al igual que al resto de los miembros del "clan de Tarancón". Fue a partir de 1844 (tras la vuelta de María Cristina y Fernando a Madrid) cuando se le abrió el camino eficaz para el ascenso social a través del matrimonio, cosa que consiguió cuando, el 30 de octubre 1846, la reina le concedió «su Real permiso para contraer matrimonio con el excelentísimo general D. José Fulgosio» ${ }^{67}$. A partir de entonces, la carrera de Fulgosio ascendió socialmente y se situó en la casa de Isabel II. El 19 marzo 1847 la reina le nombró gentil hombre de cámara con ejercicio y, poco después, el 30 noviembre de 1847, «S.M. la reina se dignaba dispensar del pago de la media anata honorífica que debe satisfacer en la Real Tesorería por el destino de gentil hombre de cámara" a la vez que ascendía Alejandra en la corte ${ }^{68}$.

La familia Fulgosio venía sirviendo la casa real desde que Fernando VII era príncipe. El abuelo, don Juan Fulgosio, fue Jefe de la Real guardarropa, y por sus servicios, Fernando VII se dignó (el 5 de abril de 1808) conceder a don Francisco Javier Fulgosio, hijo del suplicante, la plaza de caballero paje; pocos años después, el 24 enero de 1816, era nombrado $2^{\circ}$ teniente de la guarda Valona. A su vez, Francisco

64 AHN, Diversos Títulos Familias, 3390, leg. 93, exp. 7, doc. 253. Carta de Aniano a Fernando Muñoz, fechada el 13 octubre 1843.

${ }^{65}$ AHN, Diversos Titulos Familias, 3390, leg. 93, exp. 7, doc. 250.

${ }^{66}$ AHN, Diversos Títulos Familias, 3543, leg. 7, exp. 42, doc. 3.

${ }^{67}$ AGP, Personal, caja 730, expediente 21. Alejandra fallecía el 8 de septiembre 1865, con 42 años, «viuda del Excmo Sr. José Fulgosio, teniente general de los ejércitos nacionales; hija legítima de los Excmos Señores Don Juan Muñoz y Funes y Doña Eusebia Sánchez Ortega, condes de Retamoso. Vivía en la calle Atocha número 67».

68 AGP, Personal, caja 16933, exp. 21. 
Javier Fulgosio, nieto, entró de paje de S. M. y gentil hombre de cámara ${ }^{69}$. El 28 de julio de 1848, Isabel II le concedió la llave de gentilhombre de cámara con ejercicio ${ }^{70}$. Por su parte, Fernando Fulgosio, el hijo menor, apoyado en sus hermanos consiguió ser nombrado mayordomo mayor de semana de su Majestad (el 24 noviembre 1848) con el sueldo 18.000 reales anuales. ${ }^{71} \mathrm{El} 8$ abril 1859 contraía matrimonio con doña Eloisa Borris, hija del comandante retirado D. Domingo y de $\mathrm{D}^{\mathrm{a}}$ Francisca Sáenz de Tejada y Moreno ${ }^{72}$. Fernando Fulgosio fue expulsado del cargo en octubre de 1868, tras la revolución que destronó a la reina.

De esta manera, los orígenes sociales de Alejandra se disolvían dentro de una elite social de altos servidores de la casa real y con proyección en las familias más reputadas de la corte.

- La actividad de Gregorio y Jesús Muñoz

Los otros hermanos no tuvieron un papel tan relevante en política, pero hicieron carrera en los negocios de la época, consiguiendo formar grandes fortunas.

Gregorio Muñoz ingresó en la Compañía de Jesús. El afán de Fernando por querer formar un grupo fuerte y cohesionado en la corte, con influencia política, le llevó a proponerle como diputado en Cortes, lo que no pudo efectuarse debido a su condición de jesuita. Así lo cuenta Ángel Fernández de los Ríos, amigo de Fermín Caballero, en su obra Luchas politicas en la España del siglo XIX ${ }^{73}$.

Por su parte, Jesús Muñoz y Sánchez, fue nombrado caballero de la orden de Calatrava, oficial de la Legión de Honor de Francia, gentil-hombre de Cámara con ejercicio, maestrante de Granada y senador del Reino. Se casó con doña Dolores de Remisa y Rafo (dama noble de Luisa Fernanda), segunda marquesa de Remisa; matrimonio que tuvo cuatro hijos, que fueron María Cristina, Jesús Eusebio, Teresa de Jesús y Juan Gualberto Muñoz y Remisa ${ }^{74}$. Jesús Muñoz fue el miembro de la familia que triunfó como gran empresario, introducido en el círculo de grandes burgueses de la mano de su suegro, el marqués de Remisa, propietario de las salinas de Belinchón ${ }^{75}$ (Cuenca), quien, en 1844, había colaborado en la creación de la banca de Isabel II en Madrid $^{76}$, junto con el marqués de Salamanca y el banquero Nazario Carriquiri, como

\footnotetext{
${ }^{69}$ Palacio 3 de abril de 1808 «El rey se ha servido para la plaza de paje de S.M. que ha vacado por ascenso de Juan Yanguas ayuda de cámara de S.M. a D. Francisco Javier Fulgosio».

${ }^{70}$ AGP, Personal, caja 16933, expediente 23.

${ }^{71}$ En este nombramiento contaba con 18 años de edad.

72 AGP, Personal, caja 16933, expediente 20.

73 Ángel Fernández de los Ríos, Luchas políticas en la España del siglo XIX (Madrid. English y Gras, 1880-1886), II, 186.

${ }^{74}$ Blasón de España, libro de oro de su nobleza: reseña genealógica y descriptiva de la Casa Real y Grandeza de España y los títulos de Castilla. Parte primera: casa real y grandeza de España, 187-188.

75 Pedro Navascués Palacio, Un palacio romántico. Madrid, 1846-1858 (Madrid: El Viso, 1983), 9. Señala que (en 1841) el marqués de Salamanca se hizo cargo del monopolio de la sal, para sanear su administración y obteniendo pingües ganancias, para lo que se valió de la ayuda del marqués de Remisa.

${ }^{76}$ José María Zavala, Pasiones regias. De los Saboyas a los Borbones, las intrigas palaciegas más desconocidas y escandalosas de la historia (Barcelona: Plaza Janes, 2017), 45 ss.
} 
socios. Dos años después de su creación, el banco se vio en apuros económicos debido a la mala gestión. El marqués de Salamanca, que era el ministro de Hacienda, intentó fundirlo con el banco de San Fernando, pero los auditores descubrieron la precaria situación que tenía. Fernández de los Ríos, director de los periódicos la Ilustración y las Novedades denunciaba el monopolio en que se había convertido la bolsa, dominada por el clan de los Muñoz. El matrimonio de la hija de Remisa con Jesús Muñoz, vino a solventar estos problemas y a realizar nuevos negocios, como las obras del ferrocarril Madrid-Aranjuez (1851) o Madrid-Toledo (1858) y otras de mayor envergadura en las que ya estaba interviniendo también Jesús Muñoz, quien a finales del reinado de Isabel II se había convertido en uno de los hombres más ricos de España.

\subsection{Los otros miembros del "clan de Tarancón"}

Construir toda la red clientelar que formó el "clan de Tarancón" resulta imposible realizarla aquí dado del espacio que dispongo, que contrasta con la amplitud y gran número de componentes, pero también, por la influencia que ejercieron muchos de sus miembros en "cargos inferiores" relacionados con la casa real. Por ello, me limitaré a referir solamente a los que desplegaron mayor relevancia y protagonismo.

Rafael Muñoz y Funes, tío de don Fernando Muñoz, había nacido en Tarancón el 8 de abril de 1775. Fue hijo de Francisco Javier Muñoz, sargento primero que fue del regimiento provincial de Alcázar de San Juan y de $\mathrm{D}^{\mathrm{a}}$ Eugenia Funes, que tuvo el «honor de lactar a la Serma. $\mathrm{S}^{\mathrm{a}} \mathrm{D}^{\mathrm{a}}$ Carlota, reina fidelísima que tuvo honor de Portugal, de la que es hermano de leche». Por dicho mérito, Carlos IV le concedió la nobleza hereditaria, por lo que su hijo, Rafael Muñoz pudo hacer carrera eclesiástica. Por mediación de Fernando Muñoz fue nombrado rector de la Iglesia de San Pascual en el Real Sitio de Aranjuez y, poco después, teniente de la real capilla parroquial de San Antonio de la Florida. Como sucediera con los miembros del «clan de Tarancón», fue expulsado por Agustín de Argüelles en 1841; pero volvió a ocupar sus cargos tras la caída de Espartero. De esta manera, Rafael Muñoz fue repuesto en la plaza de teniente de la real capilla parroquial de san Antonio de la Florida en 1844 y por «Real decreto autógrafo de S. M. comunicado desde Mondragón en 25 de agosto de 1845, fue nombrado rector de la Real Iglesia de San Pascual de Aranjuez con el mismo sueldo de doce mil reales que ya disfrutaba cuya gracia es personal» ${ }^{77}$.

Julián Muñoz y Funes también era tío de Fernando Muñoz, fue colocado como depositario de la madera y materiales del real sitio de Aranjuez hasta que Agustín Argüelles lo expulsó del cargo el29 de octubre de 1841. Al saldar sus cuentas por el despido, se lee que Julián Muñoz y Funes, natural de Tarancón, estaba casado y tenía 44 años. En su expediente a la hora de su cese, consta que había ocupado los siguientes cargos: el 31 de octubre de 1834 fue nombrado depositario de maderas y materiales del real heredamiento de Aranjuez, cargo que finalizó en abril de 1839. Por real orden del 29 de marzo de 1845 fue nombrado administrador del Real sitio de la Isabela. Tras el regreso de la Reina Regente y Fernando Muñoz, el 23 febrero 1844 se le daba el

\footnotetext{
77 AGP, Personal, caja 729, exp. 9.
} 
puesto en posesión de la plaza de depositario de materiales en calidad de interino a D. Julián Muñoz y Funes. Por real orden de 11 febrero se le confirió la propiedad de este destino, al mismo tiempo que se le nombró, el 29 de marzo 1845, «teniendo en consideración los méritos de usted se ha dignado promoverle al destino de Administrador del Real Sitio de la Isabela con sueldo señalado en la planta ${ }^{78}$.

Gran proyección social y política tuvo Juan González Cabo-Reluz, natural de Tarancón, primo de Marcos Aniano. El 2 de junio de 1836, la Reina Gobernadora lo nombraba preceptor de sus dos amadas hijas menores, Isabel (la reina) y Luisa Fernanda, con el sueldo de 40.000reales anuales. A la hora de su jubilación, en 1840 (tenía 64 años), presentaba el siguiente expediente administrativo: durante ocho años ejerció su carrera literaria pues obtuvo los grados de licenciado y doctor de teología. Posteriormente por una Real cédula del 2 de junio de 1804 fue cura de la Iglesia de la Santísima Trinidad de la villa de Alarcón desde 20 de julio de 1804 hasta 25 de octubre de 1819. El 18 de diciembre de 1832 fue nombrado profesor de Geografía e Historia del colegio de cadetes de artillería hasta febrero de 1833, pues, el 15 de febrero fue nombrado catedrático de economía de esta corte hasta octubre del mismo año. Posteriormente, por real orden del 28 de septiembre de 1833, durante un año y un mes, fue director del colegio de humanidades de Monforte de Lemos. El 1 de diciembre de 1834 se le nombraría bibliotecario $2^{\circ}$ de la Biblioteca Nacional hasta el 3 junio de 1836. En este último día obtuvo el cargo de preceptor de su Majestad la reina Isabel y de su hermana hasta el 10 de octubre de 1840, fecha en la que se jubiló. Con todo, el 7 de agosto de 1843, María Cristina le otorgaba un nuevo cargo: «atendiendo a los servicios, conocimientos y demás circunstancias de D. Juan González Cabo-Reluz, como tutor de S.M. y en su Real nombre, he tenido a bien nombrarle bibliotecario particular de S.M. con el sueldo de 16.000r». Falleció el 18 de enero de 1858.

Acisclo Antonio Ballesteros, había nacido el 17 de noviembre de 1795 en la villa de las Cuevas de Velasco, (provincia de Cuenca); alcanzó la plaza de sacristán de gastos de la real capilla el 15 de enero de 1846. Acisclo era hijo legítimo de José Estanislao Ballesteros y de María García, labradores de dicha villa. Había estudiado en el seminario conciliar de Cuenca gramática latina, dos años de filosofía, cuatro de teología eclesiástica y uno de sagrada escritura ${ }^{79}$.

Don Serafín Valero era «hijo del dómine de Tarancón» fue nombrado administrador de la real posesión de Vista Alegre en 1835; posteriormente, en 1846, gentilhombre de Cámara; con un sueldo de 15.000 reales anuales. La amistad que Valero mantenía con Fernando Muñoz era muy estrecha ya que, no solo le informaba de todas las habladurías de los sitios reales, sino que además le administraba la economía de algunos negocios como los que tenía en La Habana.

Junto a Valero, otros amigos o conocidos de Fernando Muñoz fueron colocados en puestos de la administración. Así, eligió a don Miguel López Acebedo como director de la Casa de la Moneda; a don Antonio García del Castillo, afrancesado,

\footnotetext{
78 AGP, Personal, caja 729, exp. 8.

${ }^{79}$ Falleció el 16 de abril de 1847. Su expediente en, AGP. Personal, caja 16517, exp. 1.
} 
administrador que ha sido de la Casa de Campo y del alcázar de Sevilla, de los que no tenemos más noticia que eran amigos o conocidos de Muñoz ${ }^{80}$.

\section{CONCLUSIÓN: LA TRANSFORMACIÓN DEL «CLAN DE TARANCÓN»}

Fernando Muñoz había conseguido transformar su "clan" familiar en una facción cortesana fiel que tenía los mismos objetivos e intereses sociales y económicos y que para lograrlos se olvidaba con frecuencia el cumplimiento de las leyes civiles y de las normas éticas, lo que llevaba a Fermín Caballero, testigo de este proceso, a describir la situación de la siguiente manera:

La codicia que se ha asociado a este género de vida es espantosa. Extracciones de alhajas, cuadros y preciosidades; venta de cuanto había en los palacios reducible a dinero, negociaciones escandalosas a nombre del tesorero Gaviria ${ }^{81}$; venalidad y corrupción para recibir gruesas sumas de los ministros y contratistas, todo lo hemos palpado. El negocio de los azogues, que tanta diligencia ha producido contra Toreno, no valió menos a Cristina que al conde, por eso no se apurará jamás la verdad en este puerco asunto ${ }^{82}$.

La Regencia de Espartero trató de evitar esta corrupción y salvaguardar los bienes del patrimonio real de la rapiña a que estaban siendo sometidos. Para ello dictó un decreto en el que declaraba la formación de una comisión que se encargaría de «la formación de los inventarios de las alhajas y efectos de las casas Reales y de todo lo demás perteneciente al patrimonio de S.M. la reina y de su Augusta Hermana la Infanta Doña María Luisa Fernanda ${ }^{83}$.

No obstante, el general Espartero consiguió permanecer en la Regencia muy poco tiempo y los miembros del «clan de Tarancón» volvieron a ocupar los cargos que se vieron obligados a abandonar y, lo que es más importante, a participar en los negocios que ofrecía el Estado liberal, sustentado por la nueva estructura social, en la que fácilmente se introdujeron. Lo significativo de este proceso fue que, semejante ascenso social se produjo a partir del prestigio e influencia que aún ejercía el servicio en la Casa Real, cuando precisamente este organismo había perdido todo su poder y riqueza que había tenido en la Monarquía del Antiguo Régimen, a favor de otras instituciones contenidas en la estructura del Estado liberal. Considero que lo revolucionario de este cambio ha llevado a los historiadores a no percatarse del proceso de ascenso de determinados grupos sociales valiéndose del prestigio e influjo de la

${ }^{80}$ Fermín Caballero, La cuestión de la Regencia y el Casamiento de María Cristina de Borbón, 25-31.

81 AGP, Personas, caja 10900, expediente 5. Manuel Gaviria y Alcoba, tesorero general de la Real Casa. Gentil hombre de Cámara. Nombramiento como gentil hombre de cámara con ejercicio. Año 1840. Separado el 16 de marzo de 1842. Repuesto por decreto de S.M. de 14 de agosto de 1843.

${ }^{82}$ Fermín Caballero, La cuestión de la Regencia y el Casamiento de María Cristina de Borbón, 23.

${ }^{83}$ Decreto del 2 de diciembre de 1840, El duque de la Victoria, presidente en Discusión de las Cortes sobre la tutela de S. M. la Reina Doña Isabel II y su Augusta hermana, con otros discursos y documentos que la esclarecen, 19. 
institución real y mucho menos de la incorporación de la propia familia real en el proceso económico burgués como sucedió durante la regencia de María Cristina de Borbón. Ello lo estudiaré en próximos trabajos. 


\section{REFERENCIAS BIBLIOGRÁFICAS}

Alcalá Galiano, Antonio, Historias de las Regencias (1833-1843) (Pamplona: Urgoiti Editores, 2012).

_, Argüelles, el intendente general en comisión de la misma (Madrid: Aguado, impresor de Cámara de S.M., 1842).

Artola, Miguel, Partidos y programas políticos, $1808-1836$ (Madrid: Aguilar, 1977).

Artola, Miguel y Flaquer Montequi, Rafael, La Constitución de 1812 (Madrid: Iustel, 2008).

Bahamonde Magro, Ángel y Cayuela Fernández, José “Traficantes, armadores y hacendados: elite colonial hispano-cubana y trasvase de capitales en el siglo XIX" Studia Historica: Edad Contemporánea 15 (1997): 9-20.

Benito Ortega, Vanesa; Garzón Guzmán, Isabel; González Pañero, Juan Antonio y Mairal Domínguez, María del Mar, "La Jefatura de Oficios y Aposentamiento de la Real Casa y Patrimonio (1814-193)" Sitios Reales (2007):48- 50

Bermejo, Ildefonso, La Estafeta de Palacio (Historia del reinado de Isabel II). Cartas trascendentales (Madrid: Imprenta de R. Labajos, 1871-1872)

Burdiel, Isabel, Isabel II (Madrid: Taurus, 2011).

Burgos, Augusto de, Blasón de España, libro de oro de su nobleza: reseña genealógica y descriptiva de la Casa Realy Grandeza de España y los títulos de Castilla. Parte primera: casa realy grandeza de España (Madrid: imprenta de don Pedro Monter, 1859).

Caballero, Fermín, La cuestión de la Regencia y el Casamiento de María Cristina de Borbón (Madrid: Imprenta del Nuevo Rezado, 1840).

Casado Sánchez, María Ángeles, "María Cristina de Borbón. Una regente cuestionada" La imagen del poder. Reyes y Regentes en la España del siglo XIX. Emilio Laparra López (Coord.) (Madrid: Síntesis, 2011): 148-156.

Cos Gayón, Francisco, Historia jurídica del Patrimonio Real (Madrid: Imprenta de Enrique de la Riva, 1881).

Díaz Marín, Pedro, La monarquía tutelada. El progresismo durante la Regencia de Espartero (1840-1843). (Alicante: Publicacions Universitat d'Alacant, 2015). 
Donoso Cortés, Juan, Historia de la Regencia de la reina doña María Cristina de Borbón, edición de María Rafaela Seguí Terol (Madrid: Centro de Estudios Políticos y Constitucionales, 2016).

Fernández García, Antonio, La Constitución de Cádiz (1812) y Discurso preliminar a la Constitución (Madrid: Castalia, 2002)

Fernández de los Ríos, Ángel, Luchas políticas en la España del siglo XIX (Madrid: English y Gras, 1880-1886): II.

García Monerris, Carmen y Encarna, "La nación y su dominio: el lugar de la Corona" Historia Constitucional (Revista electrónica) 5 (2004): 160-191.

_, "Monarquía y patrimonio en tiempos de Revolución en España" Diacronie. Studi di Storia Contemporanea 16 (2013): 1-20.

_, Las cosas del rey (Madrid: Akal, 2015).

Garrido Muro, Luis, Guerra y Pa\%. Espartero durante la Regencia de María Cristina de Borbón (Madrid: Centro de Estudios Políticos y Constitucionales, 2016).

González Cuevas, Pedro Carlos, Historia de las derechas españolas (Madrid: Tecnos, 2000)

Guzmán de León, Antonio, El último Borbón. Historia dramática de Isabel II, desde sus primeros años hasta su caída del trono (Barcelona: José Zamora, editor 1868).

Heros de las Bárcenas, Martín de los, Memoria que acerca del Estado de la Real Casa y Patrimonio, y su administración en los últimos cinco meses de 1841, presenta al Excmo. Señor Tutor de S. M. D. Agustín Argüelles, el intendente general en comisión de la misma, Madrid, [s. n.], 1842. (Aguado, impresor de Cámara de S. M.).

Jiménez Landi, Antonio, Esos días (Madrid: Aguilar, 1965).

Laparra López, Emilio, Fernando VII: un rey deseado y detestado (Barcelona: Tusquets editores, 2018).

Marliani, Manuel, La Regencia de D. Baldomero Espartero, conde de Luchana, duque de la Victoria y de Morella, y sucesos que la prepararon (Madrid: Imprenta de Manuel Galiano, 1870).

Menéndez Rexach, Ángel, La jefatura del Estado en el Derecho público español (Madrid: Universidad Autónoma de Madrid, 1978). 
_, "La separación entre la casa del rey y la administración del Estado (18141820)" Revista de Estudios politicos 55 (1987): 55-121.

Molas Ribalta, Pere, Del absolutismo a la constitución. La adaptación de la clase politica española al cambio de régimen (Madrid: Silex, 2008).

Navascués Palacio, Pedro, Un palacio romántico. Madrid, 1846-1858 (Madrid: El Viso 1983).

Ortúzar Castañer, Trinidad, Fernando Agustin Muñoz Sánchez, Diccionario Bibliográfico Español. En http://dbe.rah.es/biografias/6588/agustin-fernando-munoz-ysanchez.

Pérez Núñez, Javier, "Los amigos de Espartero: la construcción de la red de los Ayacuchos" Ayer 105 (2017): 79-102.

Periódico "El labriego", sábado 10 octubre 1840. № 53

Ramos Santana, Alberto, Constitución politica de la Monarquía española, promulgada en Cádiz. el 19 de marzo 1812, y Discurso preliminar leído en las Cortes al presentar la Comisión de Constitución el proyecto de ella (Cádiz: Servicio de Publicaciones Universidad de Cádiz, 2010).

Reglamento de la real casa (Madrid: Imprenta real, 1829).

Reglamento que para el régimen y gobierno de la Real Casa mandó el Rey Ntro Señor que se observase por su Real Decreto de 16 de noviembre de 1822.

Romanones, conde de [Álvaro Figueroa y Torres], Espartero, el general del pueblo (Madrid: Espasa-Calpe, 1932).

Roncal, Antonio Manuel, ¡El enemigo en palacio! (Madrid: Publicaciones Universidad de Alcalá, 2015).

Sainz de Varanda, Ramón, Colección de leyes fundamentales (Zaragoza: Acribia, 1957).

Sánchez González, Dolores del Mar, "La nueva planta para la Casa Real de Fernando VII: El Desconocido Reglamento de 17 de noviembre de 1815" Cuadernos de Historia Moderna Anejo II (2003): 311-343.

_, "El tránsito de la casa de Fernando VII a la de Isabel II: la Junta de Gobierno de la Casa Real y Patrimonio (1815-1840)" en Corte y Monarquia en España, Sánchez González, Dolores del Mar (Coord.) (Madrid: 2003): 29-66. 
Shubert, Adrián, Espartero, el pacificador (Barcelona: Galaxia Gutenberg, 2018).

Toboso Sánchez, Pilar, "Las redes de poder en el mundo contemporáneo" Ayer 105 (2017): 13-22.

Varela Suances-Carpegna, Joaquín, La Monarquía doceañista (1810-1837) (Madrid: Marcial Pons, 2013).

Zavala, José María, Pasiones regias. De los Saboyas a los Borbones, las intrigas palaciegas más desconocidas y escandalosas de la historia (Barcelona: Plaza Janes, 2017)

Recibido: 13 de diciembre de 2018

Aprobado: 15 de febrero de 2019 